\title{
Translation as Negotiation: The Making of Telugu Language and Literature
}

\begin{abstract}
$\underline{\text { Abstract }}$
In terms of the number of native speakers, Telugu (the official language of Andhra Pradesh and Telangana in the southern part of India) ranks third among Indian languages after Hindi and Bengali. This study of the literary trajectory of Telugu notes how translation was inscribed in the emergence of the Telugu language, created as it was out of a mixture of Sanskrit, tribal and Dravidian tongues. It examines the various stages of translation through which the Telugu language passed and the responses of its literary culture to translation not only from the Ramayana and the Mahabharata, but also from English canonical texts in the nineteenth and twentieth centuries.
\end{abstract}

T. Vijay Kumar

Keywords: Translation, Telugu literary history, canon formation, historical analysis, literary culture.

\section{Telugu language}

Translation in Telugu, as perhaps in most Indian languages, is more practised than theorised. In a multilingual country like India where almost everyone is at least bilingual, translation - both in letter and spirit - is bound to have connotations quite different from those in the West. Sujit Mukherjee points out that "Rupantar (meaning 'change in form') and anuvad ('speaking after' or 'following') are the commonly understood senses of translation in India, and neither term demands fidelity to the original" (80). He 
further observes, "The notion that every literary translation is a faithful rendering of the original came to us from the West, perhaps in the wake of the Bible and the need felt by Christian missionaries to have it translated into different Indian languages" (80). Contrasting the "very relaxed" attitude in India towards translation with the Western attitude, G. N. Devy writes in a similar vein: "The implicit idea of translation as a fall from the origin and the ethical and aesthetic stigma attached to it are foreign to Indian literary culture" (XIII).

Taking translation not as an act of 'carrying across' - a text from one fixed language and culture into another-but as a process of negotiation of power, this essay argues that Telugu language as well as Telugu literature have been 'formed' through processes of linguistic, cultural, and political negotiations. The first part of the paper offers a brief overview of Telugu language to show how it has evolved by accommodating the influences of dominant languages without losing links with its linguistic siblings. The second part outlines the various phases of Telugu literature and focuses on two of them - the Age of Puranas and the Modern Period - to illustrate the contribution of translations to the growth of original literature.

Telugu is a Dravidian language spoken by about 74 million people (according to the 2001 Census; excluding second-language speakers, and the diaspora) in the southern Indian states of Andhra Pradesh, Telangana, and neighbouring states, as well as in countries outside India such as Bahrain, Fiji, Malaysia, Mauritius, Singapore and the United Arab Emirates as well as in USA, UK, Australia. In terms of the number of native speakers, Telugu ${ }^{1}$ ranks third among the Indian languages. The Telugu alphabet is a descendant of the Brahmi script of ancient India, and Telugu often exhibits a clear dichotomy between the written and spoken styles, in addition to a number of 
sharply distinct local and regional dialects and divisions between Brahmin, non-Brahmin, and Dalit speech and, more recently, writing.

Ethnologists extend various explanations for the etymology of the word 'Telugu'. While some suppose it to be a corruption of the Sanskrit 'Trilinga' ('the country of the three lingas'), others trace its roots to the Proto-Dravidian 'Tenungu' ('ten' = south; 'tenungu' $=$ Southerners). Still others insist that the word 'Telugu' owes its origin to tribal languages such as Gondi (telu $=$ white + unga (Gondi) $=$ plural form: "Telunga"= people of fair complexion) ${ }^{2}$ While it might be impossible, and even unnecessary, to decide in favour of any one of these explanations, the diversity of possible sources of the name does provide a clue to the plural heritage of the language and its composite character.

While the earliest Western account of the Telugu language was given by Frederic Bolling (1640?-1685) in Friderici Bollingii ... (1678; the full title runs into a paragraph!), the first European to make a systematic study of the language was the German Lutheran missionary Benjamin Schultze (1689-1760). To Schultze goes the credit of publishing the first book on Telugu grammar, Grammatica Telugica (Buddi kaligina vANdla lopala vokadokadiki punyapudova cUpincce nUru jnAna va;anAla ciMnna pustakaM (Mores Vitamque Christano digmam delineanles, 1747,1728), and the first printed book in Telugu, Mokshaniki Konchu Poyye Dova (Via sive Ordo Salvtis) (1746). Besides being the earliest translator of the Bible into Telugu (the New Testament by 1727, and the Old Testament by 1732), Schultze also published several Telugu books - Catechismus telugicus minor (1746), Colloquium religiosum telugice (1747) and so on. ${ }^{3}$ 
The history of the Telugu language is a history of survival and self-enrichment through negotiation with the other and often dominant languages, as we shall see below. It is possible to identify four broad stages in the history of the Telugu language:

1. 200 B.C.E-500 C.E.

2. $500-1100$ C.E.

3. 1100-1400 C.E., and

4. 1400-1900 C.E.

During the first phase (200 B.C.E. -500 C.E.) we only come across Telugu place names and personal names in Prakrit and Sanskrit inscriptions found in the Telugu country. Telugu was exposed to the influence of Prakrit as early as the third century B.C.E. The language of the people was Telugu, but the language of the rulers was Prakrit. Battles between the Guptas of North India and the Pallavas of South India during 400-500 C.E., however, quite effectively killed the royal language. For the next 500 years, Telugu was influenced by Sanskrit, and it is from Sanskrit that Telugu absorbed the tatsamas (Sanskrit equivalents).

For the next nearly four and a half centuries during the Satavahana rule (230 B.C.E-207/210 C.E.), Prakrit was the royal language in Andhra. Tadbhavas (Sanskrit derivatives) from Prakrit infiltrated the Telugu language, but Telugu did not die. It incorporated the words it needed from Prakrit and discarded the rest.

In the second phase (500-1100 C.E.) the literary languages were confined to poetic works, flourishing in the courts of kings and among scholars. Phonetic changes that occurred in the popular language are reflected in the literary language, although the two streams remained apart in grammar and vocabulary. Telugu came 
Translation as Negotiation:

The Making of Telugu Language and Literature

under the direct influence of Sanskrit about this period. It appears that literature also existed in Telugu during this time, because we find literary style in the inscriptions some three centuries before what is regarded as the first literary work in Telugu-Nannaya Bhattu's Mahabharatam. However, it was during 1000-1100 C.E.with Nannaya's Mahabharatam, and with Telugu being used extensively in inscriptions and poetry-that Telugu re-established its roots and dominated over the royal language, Sanskrit. During the time of Nannaya, the popular language diverged considerably from the literary language.

During the third phase (1100-1400 C.E.) the literary language became stylized and rigid, closing itself off from the influence of contemporary spoken language. ${ }^{4}$ During the fourth period (1400-1900) many changes took place, culminating in today's form of Telugu. The prose language of the nineteenth century shows educated speech as the basis, with occasional influences from the literary language. Also evident is the influence of the Urdu language on Telugu before the spread of English education.

What emerges from the foregoing overview of the history of the Telugu language is the fact that what is regarded today as canonical Telugu - the modern, standard Telugu-had its beginnings in the desi, spoken dialect, and the language was formed and progressively enriched through its continuous transactions on the one hand with other languages of its family - tribal languages such as Gondi, Konda, Kui, Kuvi, Pengo, and Manda - and on the other with languages which, for political and historical reasons, were the dominant languages - Sanskrit, Prakrit, Urdu, and English. No wonder that many Telugu words are 'synthetic' - formed through a combination of units from different languages (Dravidian words 
with non-Dravidian prefixes and suffixes, for example). Telugu vocabulary is therefore classified by linguists into four groups: tatsamamulu (Sanskrit equivalents), tadbhavamulu (Sanskrit derivatives), desiyamulu (indigenous words), and anyamulu (others or foreign words).

The composite nature of Telugu has led some critics to conclude that, perhaps, the language lacks an independent identity: "Telugu contains very few original words of its own" (Chenchiah and Bhujanga Rao 16). Others, however, are not surprised that a large number of words from Prakrit and Sanskrit, and to a lesser extent from Urdu and English, should find their way into the colloquial and literary forms of Telugu. They point out that Telugu has had centuries-long relationships with Prakrit and Sanskrit in the ancient past, while Urdu and English were the languages of the rulers in more recent times. Yet, they argue, "borrowing words from another language and making them our own does not make ours the daughter of that language. ... Therefore, we can proudly claim that Telugu too is an independent language" (Arudra 13-14). Nearly two centuries ago, A. D. Campbell (1798-1857), whom C. P. Brown recognized as the "first [who] rendered Telugu literature accessible to the English reader" (dedication page), had expressed a similar view. In his introduction to Grammar of the Teloogoo Language (1816), Campbell contended that extensive borrowing from Sanskrit and writing Telugu grammars following Sanskrit tradition "can not be used in proof of any radical connexion between Teloogoo and Sanskrit" (xvi). On the contrary, Campbell held that the very classification of the words in Telugu as tatsamamulu (Sanskrit equivalents), tadbhavamulu (Sanskrit derivatives), and desiyamulu (indigenous words) by native grammarians clearly indicates that the language of the land had a source different from Sanskrit. 
Just as borrowing did not mean the lack of independence in Telugu language, translation, as we shall see below, did not signal the death of original writing in Telugu literature. Translation, in fact, inaugurated an era of creativity in Telugu literature. It is pertinent to remember here that the dichotomy between translation and original writing is, in any case, alien to Indian literary ethos, and as Sujit Mukherjee says, "Until the advent of western culture in India, we had always regarded translation as new writing" (77).

\section{Telugu literature}

\section{Telugu literature is generally divided into five periods:}

(1) Early Beginnings: the pre-Nannaya period (up to 1020 C.E.)

(2) The Age of the Puranas or the Age of Translation (1020-1509)

(3) The Age of the Prabandhas ${ }^{6}$ (1509-1618)

(4) The Period of Stagnation (1630-1850), and

(5) The Modern Period (after 1850).

Telugu language has been in existence at least from the time of the Satavahana rule (230 B.C.E-207/210 C.E.), and in the early stages songs and folk ballads were composed in Telugu using indigenous metre. These songs have remained unrecorded, however, and the first instance of written Telugu is to be found in an inscription dating from 575 C.E. Since this inscription was written in verse form using desi metre, it can be surmised that by the sixth century Telugu had reached a stage of development at which it could evolve its own metrical forms. Significantly, the first treatise on poetics in Telugu, Kavi Janasrayam, was written around 940 C.E. by Malliya Rechana - a non-Brahmin poet and patron, and a staunch follower of Jainism. It is not unreasonable to assume that a theoretical text on prosody such as that by Rechana would not have 
been possible without a substantial body of literature in verse already in circulation. Besides, recent research into Telugu literature of the pre-Nannaya period indicates the existence of a Jain text in Telugu, Adi Purana, attributed to a tenth-century poet Ponnamayya (also known as Sarva Deva) (see Arudra 112-118).

However, since no literary texts in Telugu pre-dating 1020 C.E. have so far actually been discovered, the existence of any preNannaya literature remains a matter of speculation and debate. In the absence of more concrete and complete evidence, Nannaya's Mahabharatam continues to be the 'adi kavyam' or the first literary text of Telugu literature, even if Nannaya himself may or may not be recognised as the 'adi kavi' or the first poet. What can, therefore, be safely said about the literature of the pre-Nannaya period is that there was originally a desi (of the desa or province/country/ nation) literature, indigenous and with closer affinity with Dravidian rather than Aryan literature, authored mostly by Buddhist and Jain writers who perhaps used Prakrit, one form of which is considered to be the immediate literary ancestor of Telugu. This literature was either completely destroyed during the Hindu religious revivalism of the succeeding period, or it was found inadequate, and too desi, for the requirements of the revivalist movement of the eleventh century.

Nannaya was one of the earliest representatives, if not the founder, of margi (of the marga or mainstream) Telugu-Sanskrit literature, which dates from the eleventh century. His translation of the Sanskrit Mahabharatam into Telugu in 1020 C.E. is the first piece of Telugu literature as yet discovered. This initial stage in the development of Telugu literature - $\mathrm{a}$ period covering five centuries - was marked by the introduction and extension of Sanskrit culture, mainly through translations. The impulse for translation had its origins in the revival of Brahminism and the zeal to spread Vedic 
culture contained in the Sanskrit texts. This religious revivalist movement, known as the Vaidiki movement, was a Brahminical reaction to Jainism, and its first effort was to guard against the possibility of future internecine quarrels between the followers of Siva and Vishnu by creating a composite deity, Hariharanatha.

The other feature of the Vaidiki movement was its flooding of the country with Aryan culture, and it was in pursuance of this object that extensive translations from Sanskrit into Telugu were undertaken. C. R. Reddy argues that "the real motive underlying the translation of the Mahābhärata into Telugu, with all its proBrahminical interpolations, was propaganda through the vernaculars, as a counterblast to the Buddhist and Jain propaganda, which all through was carried through Māgadhī and other vernaculars of India" (6).

The reforms of the ninth-century monk Sankara dealt a fatal blow to the power of Jainism, and by the time of Raja Raja Narendra (1019-1061), the patron of Nannaya, the long-drawn battle between Jainism and Hinduism had ended in the decisive victory of Hinduism. This victory had to be consolidated and the hearts of the people rendered immune to a possible renewal of assaults by the vanquished faiths. The opening of the flood-gates of Sanskrit culture was the final act of insurance against a relapse in the future. This explains why in Telugu literature translations mark the initial, and not as in other Dravidian languages, the later stages. The opening verses of the Mahabharatam, for instance, reveal an aggressive Hinduism in the act of consolidating its victories and taking precautions against possible attacks by enemies in the future.

The Hindu religion in its popular and non-philosophical form is embodied in the three classics: the Mahabharata (known as 
the 'fifth Veda'); the Ramayana, the story of Rama; and the Bhagavata Purana, the story of Krishna. The significant achievement of the second period of Telugu literature was the translation of all these epics into Telugu.

The colossal undertaking of translating the Mahabharata into Telugu was begun by Nannaya in the eleventh century, continued by Tikkana in the thirteenth, and completed by Errapragada (Errana, 1280-1350) in the fourteenth century. Nannaya composed the Adi and the Sabha parvas (cantos) and a part of the Aranya parva. Tikkana (1220-1300) did not begin from where Nannaya had left off; instead, he began with the Virata parva and finished the remaining fifteen parvas. It was the third poet of the Kavitraya (poet-trio), Errana, who completed the Aranya parva nearly two and a half centuries after Nannaya had left it unfinished.

In the prologue to his Mahabharata, Nannaya relates how he began the translation at the request of his royal patron, who desired to perpetuate in the language of his own kingdom this epic that celebrates the heroism of the Pandavas, of whom the king claimed to be a descendant. Nannaya's translation, however, served two other unstated purposes: by making Vedic culture accessible to common people it served a religious purpose, and as the translation of a canonical text into Telugu, it served a linguistic purpose. In other words, as a Hindu text in Telugu, it challenged the Jain-Prakrit and Buddhist-Magadhi texts.

Although Nannaya followed the basic story of Vyasa's Sanskrit Mahabharata, he drew liberally on the retellings of the original available to him in Tamil and Kannada and in the adaptations in Sanskrit drama. He freely altered the original according to his own criteria of auchitya (propriety) and his 
imagined readers. He left out parts he thought were inappropriate, enlarged sections that appealed to him, contemporized the text by introducing customs and cultural habits of his own time, and included adulatory passages on the supremacy of the Brahmin in line with the efforts of the time to secure the hegemony of the Brahmin within the caste system. The result of all this is that Nannaya created a text that is hardly a translation: "the Telugu Bharata is really an independent work of art, superior to the original in many respects" (Chenchiah and Bhujanga Rao 43). This is not, however, surprising because neither the king nor the poet ever visualized the task as carrying a text from one language into another. Raja Raja Narendra requested Nannaya to "[re-] create in Telugu" with "greater skill" the "essential meaning" of Vyasa's Mahabharata. The poet responded by saying that he would "create/write" to the best of his ability. Note that both use the word 'create/write' (rachana) and not 'translation' (anuvadamu, but perhaps the word did not even exist then!) and the aim was not to merely follow or approximate the original, but to better it.

The Telugu Mahabharatam had to wait for nearly two centuries before it was resumed by Tikkana. Besides opposition from a section of obscurantists who regarded the translation of the 'fifth Veda' as sinful, as well as the superstition ${ }^{7}$ surrounding the Aranya parva, it was the difficulty of finding a worthy successor to Nannaya that delayed the translation. There is an interesting, though historically and chronologically untenable, story about how Tikkana came to be chosen. With a view to discovering a poet to match Nannaya's eminence, Raja Raja Narendra circulated a stanza, considered to be Nannaya's best, throughout his realm, inviting other poets to compose a similar stanza embodying the same idea. After many attempts were rejected as unworthy, the council of pundits received a submission from a poet who simply copied the 
original stanza and coloured it red. The council interpreted this act as an announcement by the poet that he could not only compose like Nannaya, but even excel him by adding lustre to his composition. That self-confident poet was Tikkana.

Tikkana showed marked originality not only in his prologue - in which he condemned his incompetent contemporaries who sought recognition without paying attention to technique and composition - but also in his method of translation. It is said that he undertook to dictate his verses in open court, without referring to the Sanskrit original, and that he made a vow that if ever he hesitated for a word he would cut off his tongue. Tikkana composed so quickly that pundits found it difficult to take down what he delivered, till at last they found, at the poet's own suggestion, an amanuensis who could match Tikkana's speed.

Fifty years after Tikkana, Errana relates how Tikkana appeared to him in a dream and encouraged him to finish the Mahabharatam. He completed the portion of Aranya parva left unfinished by Nannaya, but so potent was the belief that the poet who attempted the parva would come to grief that Errana made it appear that it was Nannaya who completed it, by dedicating it to Raja Raja Narendra, the royal patron of Nannaya. Errana's skill as a poet is manifest in the fact that he begins his translation in the style of Nannaya and, imperceptibly, passes into that of Tikkana. He was able to simulate them so well that the reader does not, till $\mathrm{s} / \mathrm{he}$ is told, realize that between Nannaya and Tikkana a third poet had intervened.

The second major text of Vedic religion translated into Telugu during the Age of Translation was Valmiki's Ramayana. Although Tikkana continued the translation of the Mahabharata in 
the thirteenth century, this period was predominantly a century of Ramayana translators. In its popular and literary appeal the story of Rama seems to far excel the other epic, the Mahabharata. This is evident from the fact that while there is only one translation in Telugu literature of the Mahabharata and it took three centuries to complete, there is a surfeit of renderings of the Ramayana. From the time of Nannaya to the twentieth century, there was hardly a century that did not witness several attempts at translation of this epic. Although Valmiki's Sanskrit classic, embodying the values of Aryan culture, is considered to be the basis of these translations, the translations themselves did not always abide by the original. On the contrary, they sometimes diverged so much from the original that they were in fact independent texts in the vernacular language or were "symbolic translations" of the Sanskrit pre-text. For instance, Gona Buddha Reddi, who wrote perhaps the earliest Ramayana in Telugu, ${ }^{9}$ was "able to Dravidianise the Rāmāyaña itself" by "deftly and with ... consummate art" incorporating "South Indian legends into that Aryan poem" (Reddy 7). Translations of the Ramayana have been attempted in various verse forms, in literal prose, by a woman in all-Telugu, ${ }^{10}$ in stage version, and set to music. No epic has been so frequently or so variously translated as the Ramayana, and though Valmiki's account is usually regarded as the earliest and the most authentic, it is but one of the 'many Ramayanas' that are in circulation (see Richman).

The poet who occupies a position equal to that of the Kavitraya is Srinatha (1365-1440), who is regarded by many critics as the supreme poet of Telugu literature. He introduced several new forms into Telugu literature and initiated the evolution of the 'Prabandha' form that was to dominate Telugu literary writing for the next five centuries. Srinatha's translation into Telugu of Sriharsha's Naishada Vidvat Aushada, considered to be one of the 
most difficult kavyas ${ }^{11}$ in Sanskrit (it was called 'the medicine for the pundit' on account of its difficult style), marks the next phase of translations. Srinatha's primary objective was to tell a gripping tale (this later became the major criterion of the Prabandha form), and he freely moved between translation and transliteration to achieve this objective. In the 'Preface' he described his translation thus: "observing the nuances of the sound patterns of the original, securing the views expressed in the source text, reproducing the connotations of the original meaning, recreating the rasa (or emotion) of the original, retaining the figures of speech, preserving the auchitya [propriety], shedding the anauchitya [impropriety], this Telugu Naishadam is attempted in accordance with the original". As is apparent, Srinatha kept close to the original and took care not to lose any idea, emotion, or cadence of the original.

The closing century of the Age of Translation (i.e., the fifteenth century) saw the rendering of the Puranas into Telugu, with the most important being the Srimad Bhagavatam. The Bhagavatam is considered to be the main sacred text of the Bhakti school of Vaishnavism, and its translation can be seen as the first literary manifestation of the growing influence of the Bhakti cult and Vaishnavism in the second stage of development of Telugu literature in the reign of Sri Krishnadeva Raya (1509-1530). The Bhagavatam was translated into Telugu by Srinatha's brother-in-law, Bammera Potana (1400-1475), the outstanding poet of the fifteenth century and a staunch follower of Saivism. Potana's life was devoted to the translation of the Bhagavatam, which he dedicated to Sri Rama in spite of being persecuted by the chieftain of the Dominion. Unlike the Telugu Ramayana and Mahabharatam, the Telugu Bhagavatam is much bigger than the original; and again unlike them, parts of it (such as 'Gajendra Moksham' and 'Rukmini Kalyanam') are very popular even among the unlettered. 
Telugu literature up to 1500 may be characterized as belonging to the Age of Translation, during which the poet borrowed his theme both in substance and detail from the Sanskrit original, but the reign of Krishnadeva Raya marked the beginning of a new era of independent writing. Paradoxically, however, the Age of Translation in Telugu literature was really an age of freedom, and the so-called age of freedom (the kavya yuga) ushered in a period of bondage. When the poet borrowed the substance from Sanskrit, he retained freedom of art and expression, but when he borrowed the art from Sanskrit, he lost freedom of thought.

\section{Contact with the West through translations}

A similar paradox between bondage and freedom, originality and imitation, marks Telugu literature of the modern period (1850 onwards). A craving for translation is a congenital impulse in Telugu literature, whose history was inaugurated by an era of translations, and there is active re-emergence of the phenomenon in the nineteenth century under the influence of contact with the West. Though in both eras translations gave rise to new ways of thinking and new forms of writing, the modern era, unlike the earlier period, is witness to both endotropic and exotropic translation practices.

The earliest contact between Telugu and the West can be traced to the times of the Vijayanagara Empire and the Portuguese settlements in the sixteenth century. The first literary sign of contact with the West was the translation or adaptation of the Bible. The earliest publication in Telugu of any part of the Bible was in 1812, but long before that the Scriptures had been translated, but perhaps never published, and kavyas were written on Christian themes, sometimes by poets who were not "formal members of the Christian Church but were followers of Christ from within the Hindu 
community" (Chenchiah and Bhujanga Rao 105). Pingali Ellanaryudu was the author of Tobhya Charitra (1602), otherwise known as Sarvesvara Mahatya, which was based on an account of the life of Saint Thomas. In 1750 Mangalagiri Anandakavi wrote Vedanta Rasayanam ('Essence of Scriptures') which gives a clear and succinct account of the life of Christ, and the author shows intimate acquaintance with the scriptures and the rites of the Christian Church. Interestingly, in both the texts the Bible material is domesticated and is relocated within the structures of Telugu culture, language and thought.

Telugu culture came into closer contact with Western thought, language and literature in the second half of the nineteenth century. As the British consolidated their power, translations became the site for the mutual interpretation of cultures. While other European missionaries, merchants, and civil servants such as William Carey, William Brown and A. D. Campbell compiled grammar books, dictionaries and glossaries, the legendary Indologist C. P. Brown (1798-1884) set up in his own home and at his own expense what came to be known as "Brown's college". During his nearly 40-year career in India (1817-1855), Brown produced not only a Telugu grammar (1840; 2nd edn. 1857), a Telugu-English dictionary (1852), and an English-Telugu dictionary (1852), but also critical editions of most of the canonical works of Telugu literature. Brown's contributions to Telugu language and literature are far too numerous to be listed here. Suffice it to say that be it language or literature, popular or classical, sacred or secular, there is hardly anything of importance in Telugu that he did not compile, codify, comment on, edit, translate, or print. ${ }^{12}$

Just as multi-faceted as Brown was Kandukuri Veeresalingam (1848-1919), the cultural and literary icon of 
Telugus in the second half of the nineteenth and the early twentieth centuries. Often hailed as the creator of modern Andhra, Kandukuri exemplifies the ambivalences, tensions and, above all, the two contradictory impulses for change and conservation that characterised the era of transition. He translated simultaneously from both Sanskrit and English with a view to enriching Telugu and empowering it to face the challenges of a transitional society. Kandukuri championed the movement to modernise and deSanskritize, and he used translations from English to revive Telugu literature by introducing new forms of expression.

Kandukuri's translation of William Cowper's comic poem The Diverting History of John Gilpin (1782) was the first English verse text to be translated into Telugu. In 1800, after a five-year struggle with dramatic form, Kandukuri also successfully brought out two plays: a translation from Sanskrit of Sri Harsha's Ratnavali, and a translation from English of Shakespeare's Comedy of Errors (this became the first Shakespeare play to be staged in Andhra). With both texts Kandukuri employed what became a model for later translators: 'Telugizing' the original, which meant recreating its spirit in an idiom accessible to Telugu readers and recontextualizing the original in the ethos of the target culture. In his autobiography, Sweeya Chartira, Kandukuri explained his translation method thus: "While translating plays, I substitute the original names with our regional names, change places into Indian locations, alter those parts of the story which are contrary to our customs and conventions to make them more acceptable to our people" (140-141).

Kandukuri's translations of English short stories and particularly of Aesop's fables mark an important moment in the prehistory of the Telugu short story, the first of which appeared in 1910 (Gurajada Appa Rao's "Diddubatu”). Kandukuri translated as many 
as 150 fables and published them with illustrations in two volumes. With the fables, he did not try to appropriate the originals; instead he made a special effort to retain the cultural differences-the illustrations show men and women dressed in Western costumes. At the end of each story, however, Kandukuri added an explicit fourline statement in verse, with the first three lines summing up the story and the last line highlighting the moral. In making this structural change, Kandukuri was obviously drawing on the fabular tradition of the Sanskrit classic, the Panchatantra (c 200 B.C.E.) and implying that the morals and values contained in the stories are universal.

Kandukuri's Rajasekhara Charitra (1878) is generally regarded as the first modern novel in Telugu, though there are at least two other earlier works which could lay claim to that distinction: Mahasweta (1867) by Kokkonda Venkata Ratnam, and Sonabai Parinayam or Rangaraja Charitra (1872) by Narahari Gopala Krishnamma Shetty. Kandukuri acknowledges that his inspiration was Goldsmith's The Vicar of Wakefield (1766); in fact, he began to translate the novel in order to familiarise himself with the new genre, but abandoned the project after translating three chapters, as he felt a dissonance between this alien tale and the local culture. Although Rajasekhara Charitra does retain some parallels with Goldsmith's novel, it is more or less an independent and original work that advocates social reform of a kind familiar in colonial discourse, but often cites Hindu scriptures in support of such a program. Barely nine years after its publication, this Goldsmith-inspired novel was translated back into English by an American missionary, Rev. J. Robert Hutchinson, under the title Fortune's Wheel: A Tale of Hindu Domestic Life (1887). The trajectory and reception of this novel through its translation tells an interesting story about the appropriation, reappropriation and expropriation of discourses as part of a larger 
power struggle between cultures, races and nations. Kandukuri's work in general, and his novel in particular, thus becomes an extremely interesting example of not only the endotropic and exotropic translations that marked the beginnings of the modern period in Telugu literature, but also of the asymmetry that characterises the two practices now.

Translation in Telugu has always involved negotiating not only the authority of the original text, but also the asymmetrical power marking the relationship between the source and the target languages. Be it Sanskrit in the past, or English and Bangla during the colonial and the nationalist periods, mainstream Telugu literature has had to contend with a 'superior' literary culture. Yet, Telugu survived, indeed flourished, by domesticating the dominant other and making the other a part of itself. "[The Telugu writers] are excellent moulders. The moulds and the materials are borrowed; but the art of melting and the cunning of casting is all their own.... [They] have grafted the wild Sanskrit onto the crude Dravidian Telugu stock, and have evolved a luscious literary Telugu, which, like the mango, is unmatched for taste and colour" (Chenchiah and Bhujanga Rao 121).

Asymmetry between borrowing and lending is thus characteristic of Telugu literature. As a translator and critic says, "translation is not alien to Telugu, though it is into Telugu rather than from Telugu that translations were done" (Kesava Rao 57). Such an inheritance notwithstanding, it is only in the more recent past that "translations into Telugu came to be looked upon with aversion" and the "process of translation came to be regarded with distaste" (Kesava Rao 57). Translations are now seen as being antithetical to and stifling the growth of original writing in Telugu. The reason for such a drastic change in attitude is that while in the 
past translation was a creative engagement and gave rise to new modes of writing and new forms of expression, in the contemporary period translation became borrowing, slavish imitation and a substitute for independent work. Explaining "why there are not many translations from Telugu", Kesava Rao says, "some of the works which are considered great in Telugu are themselves translations" (57).

The consolidation of the status of English both locally and globally as the language of power has further accentuated the asymmetry between source and target languages and between endotropic and exotropic translations. There are today more translations into Telugu of a wide variety of texts, but most of them are from one single language, English. Arguably, translation in Telugu has ceased to be a process of negotiation and has become merely a product of total surrender.

\section{Notes}

1. Telugu, Tenugu and Andhra are used synonymously to refer to this language. Of the three, Telugu is the earliest and the most widely used, according to the writer, critic, and literary historian Arudra $(1-3,74)$. Ethnologue.com lists the other names of the language: Telegu, Gentoo, Tailangi, Telangire, Telgi, Tengu, Terangi, and Tolangan.

2. See Arudra (20-22) and Sastry (10-17).

3. For a useful outline of the early history of European study of Telugu, see Vol. IV of George Grierson's 11-volume work Linguistic Survey of India (1906).

4. Ketana (thirteenth century C.E.), a disciple of Tikkana (who had taken over from Nannaya in translating the Mahabharata into Telugu), expressly prohibited the use of spoken words in poetic works. 
5. Since these languages do not have a tradition of written literature, Telugu's transactions with them have been non-textual and through the rich archive of their oral literatures.

6. A literary genre of Telugu literature characterized by elaborate descriptions and ornamental reworking of a narrative contained in itihasa (ancient story, legend) or purana (Hindu sacred text). See Narayana Rao (137).

7. Various stories were in circulation to account for Nannaya's noncompletion of the parva. One of them was that Nannaya had destroyed a rival poet's translation of the Bharata, for which act of jealousy he was cursed and became mad. Nannaya's alleged madness gave rise to the belief that a similar fate would befall anyone who tried to complete the parva and thereby sought to equal the perfection of the divine text.

8. A K Ramanujan defines symbolic translation thus: "Now and then ... Text 2 uses the plot and characters and names of Text 1 minimally and uses them to say entirely new things, often in an effort to subvert the predecessor by producing a countertext. We may call such a translation symbolic" (45).

9. It is, however, attributed to a mythical poet, Ranganatha, and is generally known as the Ranganatha Ramayana (1230-40).

10. Atkuri Molla (1440?-1530?), born to a potter couple who were great devotees of god Siva, wrote what is known as Molla Ramayanam in clear, simple and colloquial Telugu without using Sanskrit words. She refused to dedicate it to the emperor Krishnadeva Raya (reign 1509-1530), himself a well-known poet, saying that it did not belong to her but to Sri Rama.

11. C. P. Brown's Dictionary Telugu-English (1903) defines $\operatorname{Ka} v y a(m)$ as "Poetry; a piece of composition, whether in verse or ornamental prose".

12. For an extensive list of Brown's publications - critical writings, edited volumes, translations from and into Telugu - and an excellent estimate of his contribution to the formation of modern Telugu cultural identity, see Schmitthenner. 


\section{REFERENCES}

Arudra. 1990. Samagra Andhra Sahityam. (Comprehensive Andhra Literature). Vol. 1 (1989). Vijayawada: Prajasakti Press.

Brown, C. P. 1827. The Prosody of the Telugu and Sanscrit Languages Explained (Andhra Geervana Chandamu).Rpt, with foreword and historical introduction by G. N. Reddy and Bangorey (Bandi Gopala Reddy). Tirupati: Sri Venkateswara University, 1977.

Campbell, A. D. 1816. "Introduction." A Grammar of the Teloogoo Language. Chennai: Asian Educational Services, 1991.

Chenchiah, P. and Raja M. Bhujanga Rao Bahadur. 1928. A History of Telugu Literature. Calcutta: The Association Press.

Devy, G. N. Jan 1994. "The afterlife of literature". The Hindu Literary Review 2 : XIII+.

Grierson, George A. 1967. Linguistic Survey of India. Delhi: Motilal Banarsidass.

Kesava Rao, D. 1995. "The twilight zone". Indian Review of Books, 5. 1, $57-58$.

Mukherjee, Sujit. 1981/1994. Translation as Discovery and Other Essays on Indian Literature in English Translation. Hyderabad: Orient Longman.

Narayana Rao, Velcheru. 1987. "Afterword". For the Lord of the Animals-Poems from the Telugu: The Kälahastī́svara Śatakamu of Dhurjati. Trans. Hank Heifitz and V Narayana Rao. Delhi: OUP.

Ramanujan, A. K. 1991. "Three hundred Rāmāyanas: Five examples and three thoughts on translation." Many Rāmāyanas: The Diversity of a Narrative Tradition in South Asia. Ed. Paula Richman. Delhi: Oxford University Press, pp. 22-49.

Reddy, C. R. 1928. "Foreword." A History of Telugu Literature. By Chenchiah and Bhujanga Rao. Calcutta: The Association Press, PP.5-8. 
Translation as Negotiation:

The Making of Telugu Language and Literature

Richman, Paula, ed. 1991. Many Rāmāyanas: The Diversity of a Narrative Tradition in South Asia. Berkeley: University of California Press.

Sastry, Vetukuri Prabhakara. 1948/1960. Telugu Merugulu (Telugu Lustre). Hyderabad: Manimanjari.

Schmitthenner, Peter L. 2001. Telugu Resurgence: C. P. Brown and Cultural Consolidation in Nineteenth-century South India. New Delhi: Manohar.

Veeresalingam, Kandukuri. 1915. Sweeya Chartira. (Autobiography). Vol. 2. Rajahmundry: Hitakarini Samajam. 